\title{
Matrix metalloproteinase gene polymorphisms and susceptibility to systemic sclerosis
}

\author{
T.F. Rech' ${ }^{1}$, S.B.C. Moraes ${ }^{2}$, M. Bredemeier ${ }^{3}$, J. de Paoli², J.C.T. Brenol', \\ R.M. Xavier ${ }^{4}$ J.A.B. Chies ${ }^{5}$ and D. Simon ${ }^{1}$ \\ ${ }^{1}$ Programa de Pós-Graduação em Biologia Celular e Molecular Aplicada à Saúde, \\ Universidade Luterana do Brasil, Canoas, RS, Brasil \\ ${ }^{2}$ Laboratório de Genética Molecular Humana, Universidade Luterana do Brasil, \\ Canoas, RS, Brasil \\ ${ }^{3}$ Serviço de Reumatologia, Hospital Nossa Senhora da Conceição, \\ Grupo Hospitalar Conceição, Porto Alegre, RS, Brasil \\ ${ }^{4}$ Serviço de Reumatologia, Hospital de Clínicas de Porto Alegre, Porto Alegre, \\ RS, Brasil \\ ${ }^{5}$ Departamento de Genética, Universidade Federal do Rio Grande do Sul, \\ Porto Alegre, RS, Brasil \\ Corresponding author: D. Simon \\ E-mail: daniel.simon@ulbra.br
}

Genet. Mol. Res. 15 (4): gmr15049077

Received August 12, 2016

Accepted November 3, 2016

Published December 19, 2016

DOI http://dx.doi.org/10.4238/gmr15049077

Copyright (C 2016 The Authors. This is an open-access article distributed under the terms of the Creative Commons Attribution ShareAlike (CC BY-SA) 4.0 License.

\begin{abstract}
The major pathological hallmark of the systemic sclerosis $(\mathrm{SSc})$ is skin and internal organ fibrosis, which results from normal tissue architecture alterations and extracellular matrix (ECM) protein deposition. ECM components are degraded by matrix metalloproteinases (MMP). Promoter region polymorphisms in MMP genes may influence gene expression, resulting in an imbalance between ECM protein production and degradation. Here, we analyzed MMP1 -1607 1G/2G (rs1799750), MMP3 -1171 5A/6A (rs3025058), and MMP9 -1562 C/T
\end{abstract}


(rs3918242) polymorphisms in relation to susceptibility to SSc and its clinical features. The patient group included 98 individuals with longstanding or recently diagnosed disease, meeting the American College of Rheumatology or LeRoy and Medsger criteria for SSc; the control group included 100 healthy blood donors. All participants were of European descent. Genotyping was performed by polymerase chain reaction followed by restriction digestion. Genotype and allele frequencies of MMP polymorphisms were similar between the two groups. In secondary analyses, significantly higher frequency of $1 \mathrm{G} / 2 \mathrm{G}$ genotype from $M M P 1$ polymorphism was observed for patients testing positive for antinuclear autoantibodies $(\mathrm{P}=0.007)$, while $1 \mathrm{G} / 1 \mathrm{G}$ genotype was associated with interstitial lung disease development $(\mathrm{P}=$ 0.018 ). The $6 \mathrm{~A} / 6 \mathrm{~A}$ genotype from $M M P 3$ polymorphism was absent in patients with calcinosis $(\mathrm{P}=0.011)$, while the $M M P 35 \mathrm{~A} / 5 \mathrm{~A}$ genotype correlated with the presence of anti-topoisomerase I antibodies $(\mathrm{P}=$ $0.009)$ and reduced diffusing capacity for carbon monoxide $(\mathrm{P}=0.024)$. These results suggest that MMP polymorphisms are not associated with SSc susceptibility, although $M M P 1$ and $M M P 3$ variants are associated with specific SSc clinical and laboratory features.

Key words: Systemic sclerosis; Matrix metalloproteinase; MMP1; MMP3; MMP9; Genetic polymorphisms

\section{INTRODUCTION}

Systemic sclerosis (SSc) is an autoimmune connective tissue disease, characterized by microvascular dysfunction, immunological alterations with autoantibody production, and skin and internal organ fibrosis (Varga and Abraham, 2007). SSc pathogenesis is multifactorial and not completely understood, but the disease can be triggered in a genetically susceptible individual by exposure to some environmental factors (Katsumoto et al., 2011; Luo et al., 2013). A marked feature of SSc is the autoantibody production and, although its actual role in the disease pathogenesis is not clear, it is known to be linked to the clinical features of SSc (Hamaguchi, 2010; Graf et al., 2012).

The major pathological hallmark of SSc is fibrosis (Katsumoto et al., 2011). The fibrotic process is characterized by the deposition of extracellular matrix (ECM) proteins on normal tissue, which alters the tissue architecture and results in a loss of tissue functionality and organ failure (Bhattacharyya et al., 2011; Katsumoto et al., 2011). Matrix metalloproteinases (MMP) are enzymes that are able to degrade ECM components (Peng et al., 2012). These are involved in normal physiological processes, as well as in pathological processes such as cell proliferation, apoptosis, inflammation, aging, cancer, and arthritis (Johnson et al., 2001; Peng et al., 2012). Polymorphisms in the promoter region of MMP genes may influence gene expression and, consequently, result in an imbalance between production and degradation of ECM proteins (Peng et al., 2012). Of the polymorphisms described for MMP genes, an insertion/deletion of a guanine at MMP1 in the position -1607 results in one allele with a single guanine ( $1 \mathrm{G})$ and another with two guanines (2G) (Johnson et al., 2001). The $2 \mathrm{G}$ allele demonstrates a two- to ten-fold increase in the expression of MMP-1 (Johnson et al., 2001).

Genetics and Molecular Research 15 (4): gmr15049077 
Moreover, in the -1171 position of the $M M P 3$ promoter region, an insertion of one adenosine gives rise to alleles having either six (6A) or five adenosines (5A); it has been previously reported that individuals with the 6A/6A genotype may have decreased MMP-3 expression (Chaudhary et al., 2010). Finally, $M M P 9$ harbors a $\mathrm{C}$-to- $\mathrm{T}$ transition at the -1562 position; the $\mathrm{T}$ allele has been associated with higher transcriptional activity compared to the $\mathrm{C}$ allele (Skarmoutsou et al., 2011).

MMP genetic polymorphisms and levels of gene expression have been associated with several diseases, including chronic obstructive pulmonary disease, coronary heart disease, rheumatoid arthritis, and systemic lupus erythematosus (Schirmer et al., 2009; Scherer et al., 2010; Bahrehmand et al., 2015; Jiang et al., 2016; Ma et al., 2015, 2016). Different studies have addressed the MMP serum levels and MMP gene expression in SSc (Young-Min et al., 2001; Kikuchi et al., 2002; Toubi et al., 2002; Meng et al., 2008; Brown et al., 2012; Frost et al., 2012). However, studies on the influence of genetic polymorphisms in $M M P 1, M M P 3$, and $M M P 9$ on SSc susceptibility are few (Johnson et al., 2001; Marasini et al., 2001; Skarmoutsou et al., 2011). In the present study, we analyzed the frequency of $M M P 1-16071 G / 2 G(\mathrm{rs} 1799750)$, MMP3 -1171 5A/6A (rs3025058), and MMP9-1562 C/T (rs3918242) polymorphisms, as well as a potential association between these polymorphic variants and clinical features of the disease, in SSc patients from Southern Brazil.

\section{MATERIAL AND METHODS}

\section{Patients and controls}

The SSc patient group was recruited from Hospital de Clínicas de Porto Alegre (HCPA, Porto Alegre, RS, Brazil) and was composed of individuals with longstanding or recently diagnosed disease, meeting the American College of Rheumatology criteria for SSc or the LeRoy and Medsger criteria for early forms of disease (LeRoy and Medsger, 2001). Patients with overlapping syndromes were excluded, except those with definite SSc diagnosis and secondary inflammatory myopathy or Sjögren's syndrome. The control group consisted of healthy blood donors from the urban population of Porto Alegre. Individuals with acute or chronic diseases, as well as a family history of genetic diseases, were excluded from this study. All patients and controls were ethnically classified as of European descent (i.e., Caucasians). This study was approved by the Ethics Committee of HCPA and Universidade Luterana do Brasil. All participants provided written informed consent.

\section{Clinical evaluation}

The procedures used for diagnosis, identification and classification of the clinical features were performed as described previously by Bredemeier et al. (2004). Pulmonary high-resolution computed tomography (HRCT) was performed during breath holding after deep inspiration in the supine position, without using an intravenous contrast agent. All HRCT scans were assessed for the presence of interstitial lung disease (ILD) (ground-glass opacities, reticular pattern, and honeycombing) by two radiologists. Spirometry and diffusing capacity for carbon monoxide (DLCO) test were also performed for most patients. Forced vital capacity (FVC) and DLCO were considered to have reduced when presenting $<80$ and $<75 \%$ of the predicted values, respectively. Doppler echocardiography was used to estimate the pulmonary systolic arterial pressure; those with values of $\geq 40 \mathrm{mmHg}$ were considered to have pulmonary hypertension $(\mathrm{PH})$.

Genetics and Molecular Research 15 (4): gmr15049077 


\section{Molecular analysis}

Peripheral blood samples were collected, and genomic DNA was extracted from them using a salting-out method (Lahiri and Nurnberger, 1991). MMP polymorphisms were evaluated by polymerase chain reaction (PCR), followed by restriction fragment length polymorphism (RFLP) analysis. Primers and conditions for the analysis of $M M P 1-1607$ $1 G / 2 G$ (rs1799750), MMP3 -1171 5A/6A (rs3025058), and MMP9 -1562 C/T (rs3918242) polymorphisms have previously been described by Dunleavey et al. $(2000 \mathrm{a}, \mathrm{b})$ and Morgan et al. (2003), respectively. The resulting amplified 119 and 111-bp PCR products of MMP1-1607 $1 G / 2 G$ (rs1799750) and $M M P 3-11715 A / 6 A$ (rs3025058) analyses, respectively, were digested using XmnI restriction enzyme (New England Biolabs, Ipswich, MA, USA). The amplified 436-bp fragment products of $M M P 9-1562 C / T$ (rs3918242) analysis were digested using SphI enzyme (New England Biolabs). Genotypes from all polymorphisms were determined by visualization on $10 \%$ polyacrylamide gel stained with silver nitrate. Positive and negative control samples were included in all analyses.

\section{Statistical analysis}

Allele and genotype frequencies were estimated by direct counting. The chi-square test was performed to compare the observed genotype frequencies with the assumptions for the Hardy-Weinberg equilibrium. The chi-square or Fisher exact test were performed to compare allele and genotype frequencies between patients and controls, and the clinical variables between genotypes. Residual analysis was used to identify the categories responsible for a significant chi-square test. All tests were two-tailed and the results were considered statistically significant when the P value was less than 0.05 . Data was analyzed using SPSS version 18.0 (SPSS Inc., Chicago, IL, USA) and WinPepi version 11.43 (Abramson, 2011).

\section{RESULTS}

We evaluated $98 \mathrm{SSc}$ patients and 100 healthy blood donors with a mean age of $49.7 \pm 14.9$ and $44.1 \pm 7.3$ years, respectively. Limited cutaneous SSc was the most prevalent disease subtype (59.2\%). Calcinosis and telangiectasia affected 23.5 and $68.4 \%$ of the patients, respectively. Anti-nuclear antibodies (ANA) were present in $85.7 \%$ of the patients, with $39.8 \%$, positive for anti-centromere antibodies, and $22.4 \%$, positive for anti-topoisomerase I antibodies. Reduced FVC and DLCO were observed in 36.7 and $85.4 \%$ of the patients, respectively. ILD affected $66.7 \%$ of the patients, and $14.6 \%$ of the patients presented PH (Table 1).

Data are represented as numbers (percentages in parentheses), except as otherwise indicated. *Data not available for all patients. dcSSc: diffuse cutaneous SSc; lcSSc: limited cutaneous SSc; ssSSc: sine-scleroderma SSc; ANA: anti-nuclear antibodies; FVC: forced vital capacity; DLCO: carbon monoxide diffusing capacity; HRCT: high resolution computed tomography.

The genotype frequencies of polymorphisms were in accordance with the expected frequencies for Hardy-Weinberg equilibrium in all groups. Allele and genotype frequencies of MMP polymorphisms were similar between patients and controls (Table 2).

Genetics and Molecular Research 15 (4): gmr15049077 
Table 1. Demographic, clinical, and laboratory data of SSc patients.

\begin{tabular}{l|c}
\hline Characteristics & SSc patients \\
\hline Male/female & $11(11.2) / 87(88.8)$ \\
\hline Age in years (mean \pm SD) & $49.7 \pm 14.9$ \\
\hline SSc subtypes & $25(25.5)$ \\
\hline dcSSc & $58(59.2)$ \\
\hline cSSc & $15(15.3)$ \\
\hline ssSSc & $9(3.5-20.0)$ \\
\hline Duration of disease in years, median $(25-75 \%$ quartiles) & $98(100.0)$ \\
\hline Raynaud's phenomenon & $5.5(2-14.2)$ \\
\hline Total skin score, median $(25-75 \%$ quartiles $)$ & $23(23.5)$ \\
\hline Calcinosis & $67(68.4)$ \\
\hline Telangiectasia & $84(85.7)$ \\
\hline ANA $\geq 1: 80$ & $39(39.8)$ \\
\hline Anti-centromere antibodies & $22(22.4)$ \\
\hline Anti-topoisomerase I antibodies & $33(36.7)$ \\
\hline Reduced FVC $(\mathrm{N}=90)^{*}$ & $76(85.4)$ \\
\hline Reduced DLCO $(\mathrm{N}=89 *$ & $62(66.7)$ \\
\hline Interstitial lung disease on HRCT $(\mathrm{N}=93)^{*}$ & $13(14.6)$ \\
\hline Pulmonary hypertension $(\mathrm{N}=89)^{*}$ &
\end{tabular}

Table 2. Comparison of allele and genotype frequencies of $M M P 1-16071 G / 2 G, M M P 3-11715 A / 6 A$, and $M M P 9-1562 C / T$ polymorphisms between SSc patients and healthy controls.

\begin{tabular}{|c|c|c|c|}
\hline Polymorphism & SSc patients N (\%) & Controls N (\%) & $\mathrm{P}$ \\
\hline$\overline{M M P 1-16071 G / 2 G}$ & 98 & 100 & \\
\hline \multicolumn{4}{|l|}{ Alleles: } \\
\hline$\overline{1 G}$ & $77(39.3)$ & $86(43.0)$ & 0.48 \\
\hline $2 \mathrm{G}$ & $119(60.7)$ & $114(57.0)$ & \\
\hline \multicolumn{4}{|l|}{ Genotypes: } \\
\hline $1 \mathrm{G} / 1 \mathrm{G}$ & $14(14.3)$ & $19(19.0)$ & 0.68 \\
\hline $1 \mathrm{G} / 2 \mathrm{G}$ & $49(50.0)$ & $48(48.0)$ & \\
\hline $2 \mathrm{G} / 2 \mathrm{G}$ & $35(35.7)$ & $33(33.0)$ & \\
\hline MMP3 -1171 5A/6A & 90 & 100 & \\
\hline \multicolumn{4}{|l|}{ Alleles: } \\
\hline$\overline{5 \mathrm{~A}}$ & $92(51.1)$ & $90(45.0)$ & 0.26 \\
\hline$\overline{6 \mathrm{~A}}$ & 88 (48.9) & $110(55.0)$ & \\
\hline \multicolumn{4}{|l|}{ Genotypes: } \\
\hline $5 \mathrm{~A} / 5 \mathrm{~A}$ & $24(26.7)$ & $24(24.0)$ & 0.36 \\
\hline $5 \mathrm{~A} / 6 \mathrm{~A}$ & $44(48.9)$ & $42(42.0)$ & \\
\hline$\overline{6 \mathrm{~A} / 6 \mathrm{~A}}$ & $22(24.4)$ & $34(34.0)$ & \\
\hline$\overline{M M P 9-1562 C / T}$ & 92 & 100 & \\
\hline \multicolumn{4}{|l|}{ Alleles: } \\
\hline$\overline{\mathrm{C}}$ & $169(91.8)$ & $184(92.0)$ & 0.99 \\
\hline $\mathrm{T}$ & $15(8.2)$ & $16(8.0)$ & \\
\hline \multicolumn{4}{|l|}{ Genotypes: } \\
\hline$\overline{\mathrm{CC}}$ & $78(84.8)$ & $84(84.0)$ & 0.69 \\
\hline $\mathrm{CT}$ & $13(14.1)$ & $16(16.0)$ & \\
\hline TT & $1(1.1)$ & - & \\
\hline
\end{tabular}

Analyses of the clinical characteristics of patients, according to genotypes of $M M P 1, M M P 3$, and $M M P 9$ polymorphisms are presented in Table 3. Significant differences were observed concerning the genotype frequencies of $M M P 1$, and the presence of ANA $(\mathrm{P}=0.007)$ and ILD $(\mathrm{P}=0.018)$. Among patients positive for the ANA test, an increased frequency of $1 \mathrm{G} / 2 \mathrm{G}$ genotype was observed, while the frequency of $2 \mathrm{G} / 2 \mathrm{G}$ genotype was significantly decreased (95.9 and $71.4 \%$, respectively). Furthermore, all patients with $1 \mathrm{G} / 1 \mathrm{G}$ genotype presented ILD.

Genetics and Molecular Research 15 (4): gmr15049077 
T.F. Rech et al.

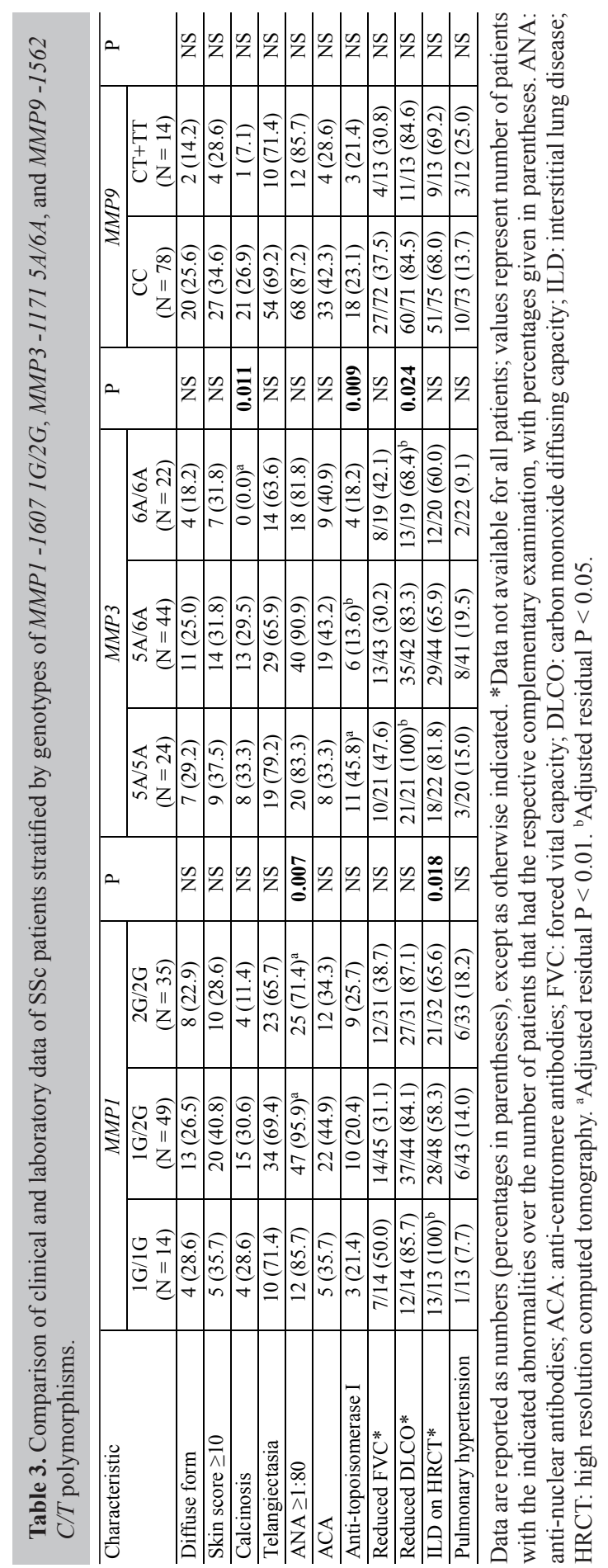

Genetics and Molecular Research 15 (4): gmr15049077 
Genotypes from the $M M P 3-11715 A / 6 A$ polymorphism were also significantly associated with specific clinical features. None of the SSc patients who developed calcinosis presented the $6 \mathrm{~A} / 6 \mathrm{~A}$ genotype $(\mathrm{P}=0.011)$. Anti-topoisomerase-I antibodies were present in 45.8 and $13.6 \%$ of the patients with $5 \mathrm{~A} / 5 \mathrm{~A}$ and $5 \mathrm{~A} / 6 \mathrm{~A}$ genotypes, respectively $(\mathrm{P}=0.009)$. Moreover, significant differences in genotype frequencies were observed in patients with reduced DLCO $(\mathrm{P}=0.024)$. All patients with the $5 \mathrm{~A} / 5 \mathrm{~A}$ genotype had reduced DLCO, while the frequency of this condition was significantly decreased $(68.4 \%)$ in patients with $6 \mathrm{~A} / 6 \mathrm{~A}$ genotype. Finally, the variants of $M M P 9-1562 C / T$ polymorphism were not associated with the clinical features of the patients.

\section{DISCUSSION}

ECM components include elastic fibers, collagen fibers, glycoproteins (fibronectin and laminin), and mucopolysaccharides. A physiological balance between the synthesis, deposit in the extracellular environment, and degradation of these molecules is required (Robert et al., 2016). MMP enzymes degrade ECM components, promoting this required balance (Johnson et al., 2001; Peng et al., 2012). Disruption of this balance results in the fibrotic process, a pathological hallmark of SSc, which causes loss of tissue functionality and the failure of affected organs (Bhattacharyya et al., 2011; Katsumoto et al., 2011; Robert et al., 2016). In this study, we investigated the role of $M M P 1-16071 G / 2 G, M M P 3-11715 A / 6 A$, and $M M P 9-1562 C / T$ polymorphisms in SSc susceptibility and the influence of polymorphic variants on the clinical features of the disease. The results showed no association between MMP polymorphisms and SSc susceptibility. However, genetic variants of MMP1 -1607 1G/2G and MMP3 -1171 5A/6A polymorphisms significantly influenced the clinical and laboratory features of the disease.

In accordance with data from a previous study performed by Johnson et al. (2001), similar frequencies for MMP1 -1607 1G/2G polymorphism were observed between patients and controls. Nevertheless, in the present study, ANA were more prevalent among patients with the $1 \mathrm{G} / 2 \mathrm{G}$ genotype than among patients with the $2 \mathrm{G} / 2 \mathrm{G}$ genotype. Furthermore, the 5A/5A genotype from MMP3 -1171 5A/6A polymorphism was linked to an increased risk for the presence of anti-topoisomerase I. It has been reported that genetic factors are associated with specific ANA, suggesting that the genetic background may contribute to the autoantibody profile (Hamaguchi, 2010).

A significant association was observed between the $1 \mathrm{G} / 1 \mathrm{G}$ genotype of $M M P 1$ and ILD development. ILD is characterized by alveolar epithelial cell damage, activation of fibroblasts, and excessive accumulation of ECM proteins in the lung parenchyma, which ultimately results in pulmonary fibrosis (Rosas et al., 2008; Murray et al., 2012). It has been reported that the $1 \mathrm{G}$ allele is associated with low transcriptional activity of MMP1 (Johnson et al., 2001), and in this context, it may result in the accumulation of ECM proteins, contributing to ILD development. Pulmonary fibrosis in SSc is associated with substantial morbidity and mortality in SSc (Rosas et al., 2008).

Our data from the analysis of $M M P 3-11715 \mathrm{~A} / 6 \mathrm{~A}$ polymorphism disagree with that from a previous study by Marasini et al. (2001) which suggested that the 6A allele is involved in SSc susceptibility. However, in our study, none of the SSc patients that developed calcinosis presented the $6 \mathrm{~A} / 6 \mathrm{~A}$ genotype. Calcinosis is characterized by formation of calcium deposits in skin and subcutaneous tissues, and it is frequently observed in connective tissues diseases. Factors that trigger the development of calcinosis are not completely understood. They may

Genetics and Molecular Research 15 (4): gmr15049077 
include damage to the ECM proteins, alterations in the mechanisms responsible for inhibition of the calcification process, and abnormalities in the mitochondrial calcium and phosphate levels (Gutierrez and Wetter, 2012). It has been previously reported that the 6A allele has two-folds lower promoter activity than the 5A allele (Chaudhary et al., 2010). This lower transcriptional activity may be responsible for protecting against calcinosis development in SSc patients with the $6 \mathrm{~A} / 6 \mathrm{~A}$ genotype. Of note and contrary to the individuals who were at a higher risk of reduced DLCO due to their $5 \mathrm{~A} / 5 \mathrm{~A}$ genotype, those bearing the $6 \mathrm{~A} / 6 \mathrm{~A}$ genotype were at a lower risk of reduced DLCO. In SSc patients, reduced DLCO generally indicates the presence of ILD and PH (Murray et al., 2012). Therefore, the 6A/6A genotype can be suggested as a genetic protection factor in the development of clinical complications from $\mathrm{SSc}$, such as calcinosis and reduced DLCO.

Some studies also detailed serum or gene expression levels of $M M P 1, M M P 3$, and MMP9 in SSc. For example, an increased serum level of MMP1, but not of MMP3, was observed among SSc patients; although, MMP1 serum levels were not attributed to SSc (Toubi et al., 2002). In another study, serum levels of tissue inhibitors of metalloproteinases (TIMP) 1 were significantly increased in SSc patients, especially those with the diffuse form in early disease (Young-Min et al., 2001). TIMP are important regulatory enzymes that are involved in MMP degradation (Murphy, 2011). A study performed with South African SSc patients reported a significant decrease in $M M P 1$ expression and an increase in TIMP-1 expression (Frost et al., 2012). Concerning MMP9, it has been previously demonstrated that expression levels are lower for MMP9 and higher for TIMP-1 in skin lesions of patients with diffuse SSc (dcSSc), as compared to those with normal skin (Meng et al., 2008). Furthermore, a study reported significantly decreased MMP9 activity in serum of dcSSc patients compared with that of healthy controls (Kikuchi et al., 2002). Despite such data, and in accordance with previous data from molecular analysis, our results suggest that there is no association between $M M P 9-1562 C / T$ polymorphism and SSc susceptibility or clinical features of the disease.

Genetic polymorphism, gene transcription, posttranslational modification, and inhibition of TIMP are all possible regulatory mechanisms of MMP(Peng et al., 2012). Thereby, the accumulation of ECM components, which results in tissue fibrosis, is not only related to polymorphisms or altered MMP gene expression, but may also be due to increase in TIMP enzyme activity, which blocks the action of MMP and inhibits matrix degradation (Murphy, 2011; Peng et al., 2012).

Our study has some limitations. Our sample was composed of prevalent cases of SSc and, therefore, more severe and aggressive cases may not have been adequately represented. Another limitation of the present study is the relatively small sample size, and this could be explained, in part, by the exclusion of individuals of African descent or of a mixed ethnic background. The major strengths of our study are the prospective data collection and the thorough clinical and laboratory evaluation of almost all patients.

To our knowledge, this is the first study that evaluated the association of polymorphisms in MMP genes in Brazilian SSc patients. In conclusion, this study suggests that there is no association between MMP polymorphisms and SSc susceptibility; although, genotypes from $M M P 1-16071 G / 2 G$ and $M M P 3-11715 A / 6 A$ polymorphisms were associated with specific clinical features of the disease, such as the presence of ANA, calcinosis, and ILD.

\section{Conflicts of interest}

The authors declare no conflict of interest. 


\section{ACKNOWLEDGMENTS}

The authors thank the Fundação de Amparo à Pesquisa do Estado do Rio Grande do Sul (FAPERGS), Coordenação de Aperfeiçoamento de Pessoal de Nível Superior (CAPES), and Universidade Luterana do Brasil (ULBRA) for their financial support.

\section{REFERENCES}

Abramson JH (2011). WINPEPI updated: computer programs for epidemiologists, and their teaching potential. Epidemiol. Perspect. Innov. 8: 1. http://dx.doi.org/10.1186/1742-5573-8-1

Bahrehmand F, Vaisi-Raygani A, Kiani A, Rahimi Z, et al. (2015). Matrix metalloproteinase 9 polymorphisms and systemic lupus erythematosus: correlation with systemic inflammatory markers and oxidative stress. Lupus 24: 597605.http://dx.doi.org/10.1177/0961203314559085

Bhattacharyya S, Wei J and Varga J (2011). Understanding fibrosis in systemic sclerosis: shifting paradigms, emerging opportunities. Nat. Rev. Rheumatol. 8: 42-54.http://dx.doi.org/10.1038/nrrheum.2011.149

Bredemeier M, Xavier RM, Capobianco KG, Restelli VG, et al. (2004). Nailfold capillary microscopy can suggest pulmonary disease activity in systemic sclerosis. J. Rheumatol. 31: 286-294.

Brown M, Postlethwaite AE, Myers LK and Hasty KA (2012). Supernatants from culture of type I collagen-stimulated PBMC from patients with cutaneous systemic sclerosis versus localized scleroderma demonstrate suppression of MMP-1 by fibroblasts. Clin. Rheumatol. 31: 973-981.http://dx.doi.org/10.1007/s10067-012-1962-z

Chaudhary AK, Singh M, Bharti AC, Singh M, et al. (2010). Synergistic effect of stromelysin-1 (matrix metalloproteinase-3) promoter (-1171 5A->6A) polymorphism in oral submucous fibrosis and head and neck lesions. BMC Cancer 10: 369. http://dx.doi.org/10.1186/1471-2407-10-369

Dunleavey L, Beyzade S and Ye S (2000a). Rapid genotype analysis of the matrix metalloproteinase-1 gene $1 \mathrm{G} / 2 \mathrm{G}$ polymorphism that is associated with risk of cancer. Matrix Biol. 19: 175-177. http://dx.doi.org/10.1016/S0945$\underline{053 X(00) 00059-7}$

Dunleavey L, Beyzade S and Ye S (2000b). Rapid genotype analysis of the stromelysin gene 5A/6A polymorphism. Atherosclerosis 151: 587-589. http://dx.doi.org/10.1016/S0021-9150(00)00443-3

Frost J, Ramsay M, Mia R, Moosa L, et al. (2012). Differential gene expression of MMP-1, TIMP-1 and HGF in clinically involved and uninvolved skin in South Africans with SSc. Rheumatology (Oxford) 51: 1049-1052. http://dx.doi. org/10.1093/rheumatology/ker367

Graf SW, Hakendorf P, Lester S, Patterson K, et al. (2012). South Australian Scleroderma Register: autoantibodies as predictive biomarkers of phenotype and outcome. Int. J. Rheum. Dis. 15: 102-109. http://dx.doi.org/10.1111/j.1756185X.2011.01688.X

Gutierrez Jr A and Wetter DA (2012). Calcinosis cutis in autoimmune connective tissue diseases. Dermatol. Ther. (Heidelb.) 25: 195-206. http://dx.doi.org/10.1111/j.1529-8019.2012.01492.x

Hamaguchi Y (2010). Autoantibody profiles in systemic sclerosis: predictive value for clinical evaluation and prognosis. J. Dermatol. 37: 42-53.http://dx.doi.org/10.1111/j.1346-8138.2009.00762.x

Jiang S, Yang ZH, Chen YY, He Z, et al. (2016). MMP-9 genetic polymorphism may confer susceptibility to COPD. Genet. Mol. Res. 15: gmr6272. http://dx.doi.org/10.4238/gmr.15026272

Johnson RW, Reveille JD, McNearney T, Fischbach M, et al. (2001). Lack of association of a functionally relevant single nucleotide polymorphism of matrix metalloproteinase-1 promoter with systemic sclerosis (scleroderma). Genes Immun. 2: 273-275. http://dx.doi.org/10.1038/sj.gene.6363768

Katsumoto TR, Whitfield ML and Connolly MK (2011). The pathogenesis of systemic sclerosis. Annu. Rev. Pathol. 6: 509-537.http://dx.doi.org/10.1146/annurev-pathol-011110-130312

Kikuchi K, Kubo M, Hoashi T and Tamaki K (2002). Decreased MMP-9 activity in the serum of patients with diffuse cutaneous systemic sclerosis. Clin. Exp. Dermatol. 27: 301-305.http://dx.doi.org/10.1046/j.1365-2230.2002.01011.x

Lahiri DK and Nurnberger Jr JI (1991). A rapid non-enzymatic method for the preparation of HMW DNA from blood for RFLP studies. Nucleic Acids Res. 19: 5444.http://dx.doi.org/10.1093/nar/19.19.5444

LeRoy EC and Medsger Jr TA (2001). Criteria for the classification of early systemic sclerosis. J. Rheumatol. 28: 1573-1576.

Luo Y, Wang Y, Wang Q, Xiao R, et al. (2013). Systemic sclerosis: genetics and epigenetics. J. Autoimmun. 41: 161-167. http://dx.doi.org/10.1016/j.jaut.2013.01.012

Ma MJ, Liu HC, Qu XQ and Wang JL (2015). Matrix metalloproteinase-3 gene polymorphism and its mRNA expression in rheumatoid arthritis. Genet. Mol. Res. 14: 15652-15659. http://dx.doi.org/10.4238/2015.December.1.17

Genetics and Molecular Research 15 (4): gmr15049077 
Ma YZ, Jiang QY and Kong DQ (2016). Association between matrix metallopeptidase 1 and type 2 diabetes mellitus coexisting with coronary heart disease in a Han Chinese population. Genet. Mol. Res. 15: gmr.15027938

Marasini B, Casari S, Zeni S, Turri O, et al. (2001). Stromelysin promoter polymorphism is associated with systemic sclerosis. Rheumatology (Oxford) 40: 475-476. http://dx.doi.org/10.1093/rheumatology/40.4.475

Meng C, Chen X, Li J, Wu Y, et al. (2008). Expression of MMP-9 and TIMP-1 in lesions of systemic sclerosis and its implications. J. Huazhong Univ. Sci. Technolog. Med. Sci. 28: 480-482. http://dx.doi.org/10.1007/s11596-008-0424-y

Morgan AR, Zhang B, Tapper W, Collins A, et al. (2003). Haplotypic analysis of the MMP-9 gene in relation to coronary artery disease. J. Mol. Med. (Berl.) 81: 321-326.http://dx.doi.org/10.1007/s00109-003-0441-z

Murphy G (2011). Tissue inhibitors of metalloproteinases. Genome Biol. 12: 233. http://dx.doi.org/10.1186/gb-2011-12-11-233

Murray LA, Rubinowitz A and Herzog EL (2012). Interstitial lung disease: is interstitial lung disease the same as scleroderma lung disease? Curr. Opin. Rheumatol. 24: 656-662.http://dx.doi.org/10.1097/BOR.0b013e3283588de4

Peng WJ, Yan JW, Wan YN, Wang BX, et al. (2012). Matrix metalloproteinases: a review of their structure and role in systemic sclerosis. J. Clin. Immunol. 32: 1409-1414. http://dx.doi.org/10.1007/s10875-012-9735-7

Robert S, Gicquel T, Victoni T, Valença S, et al. (2016). Involvement of matrix metalloproteinases (MMPs) and inflammasome pathway in molecular mechanisms of fibrosis. Biosci. Rep. 36: e00360. http://dx.doi.org/10.1042/ BSR20160107.

Rosas IO, Richards TJ, Konishi K, Zhang Y, et al. (2008). MMP1 and MMP7 as potential peripheral blood biomarkers in idiopathic pulmonary fibrosis. PLoS Med. 5: e93.http://dx.doi.org/10.1371/journal.pmed.0050093

Scherer S, de Souza TB, de Paoli J, Brenol CV, et al. (2010). Matrix metalloproteinase gene polymorphisms in patients with rheumatoid arthritis. Rheumatol. Int. 30: 369-373. http://dx.doi.org/10.1007/s00296-009-0974-8

Schirmer H, Basso da Silva L, Teixeira PJ, Moreira JS, et al. (2009). Matrix metalloproteinase gene polymorphisms: lack of association with chronic obstructive pulmonary disease in a Brazilian population. Genet. Mol. Res. 8: 1028-1034. http://dx.doi.org/10.4238/vol8-3gmr596

Skarmoutsou E, D'Amico F, Marchini M, Stivala F, et al. (2011). Analysis of matrix metalloproteinase-9 gene polymorphism $-1562 \mathrm{C} / \mathrm{T}$ in patients suffering from systemic sclerosis with and without ulcers. Int. J. Mol. Med. 27: 873-877.http://dx.doi.org/10.3892/ijmm.2011.661

Toubi E, Kessel A, Grushko G, Sabo E, et al. (2002). The association of serum matrix metalloproteinases and their tissue inhibitor levels with scleroderma disease severity. Clin. Exp. Rheumatol. 20: 221-224.

Varga J and Abraham D (2007). Systemic sclerosis: a prototypic multisystem fibrotic disorder. J. Clin. Invest. 117: $557-$ 567.http://dx.doi.org/10.1172/JCI31139

Young-Min SA, Beeton C, Laughton R, Plumpton T, et al. (2001). Serum TIMP-1, TIMP-2, and MMP-1 in patients with systemic sclerosis, primary Raynaud's phenomenon, and in normal controls. Ann. Rheum. Dis. 60: 846-851.

Genetics and Molecular Research 15 (4): gmr15049077 